\title{
Sustainable Environmental Monitoring and Database Development Method for Climate Induced Hazard Management
}

\author{
Ehiorobo J.O. ${ }^{1, *}$ and Ehigiator-Irughe, R. ${ }^{2}$ \\ ${ }^{1}$ Department of Civil Engineering, University of Benin, Benin City, Nigeria \\ ${ }^{2}$ Department of Geomatics, University of Benin, Benin City, Nigeria \\ Corresponding Author: *raphael.ehigiator@uniben.edu
}

\begin{abstract}
Nigeria is currently confronted with a myriad of environmental hazards notably flooding and erosion. The impact of these environmental hazards is discussed. Climate change as a result of global warming is likely to result in increase in the frequency of extreme weather events. Designating houses in flood prone areas, urban migration, deforestation, sea-level rise and other factors will contribute to more serious impacts and damages.. Access to available observation data is a prerequisite to improving our understanding of the consequences of on-going changes and extreme weather events and their devastating effect. In this paper, an overview of environmental factors contributing to the on-going environmental hazards and their impacts are reviewed. The creation of a database and the continuous monitoring of the environment using space based sensors and GIS not only for hazard monitoring but also for mitigation that aid in social economic development are provided. Preliminary results of work done under the EU-NEPAD Centre of Excellence in Water Science and Technology with respect to precipitation frequency analysis are presented. The paper stresses the need for institutional collaboration in creating a data base that will assist not only for early warning against disaster but serve as a database for protection against climate induced disaster that could affect infrastructures, agriculture and agro-based industries as well as national security.
\end{abstract}

Keywords: Climate Change, Precipitation, L-moment, Return Period, Skewness, Kurtosis

\subsection{Introduction}

At the moment, there are networks of weather stations that maintain records of temperature and rainfall. The most noticeable impacts of global warming is changes that are occurring in both average and extreme temperature and precipitation. As a result of global warming it is predicted that high latitudes and generally work places will receive more rainfall. Increase in rainfall will come in the form of bigger, wetter storm, rather than in the form of more raining days (NASA Earth Observation, 2016). From NASA report, it is impossible to pin any unusual weather event on global warming, but evidence in energy do suggest that global warming is already influencing the weather.

From the Intergovernmental Panel on Climate Change (IPCC, 2001) report, it was also observed that intense rainfall events have increased in frequency during the last 50 years and that human induced global warming are more likely to contribute to the trend as have been noticed within the last twenty years. Satellite based rainfall measurements shows tropical areas got more rain in the form of large storms or large rainfall instead of moderate storms.

As a result of global warming, sea level continues to rise and this has contributed immensely to coastal erosion not only in Nigeria but globally. Also, climate change is starting to have adverse effect on many countries due to global warming. The people hardest hit are inhabitants of under developed and developing countries such as Nigeria, who as a result of the current rapid drop in the price of Crude oil will not have the resources to fight disasters associated with climate change. As a result of more intense rainfall and rising sea level more damaging, flooding will be experienced. This will lead to water pollution, malnutrition and social economic problems within the Country (Ehiorobo and Izinyon 2011, Ehiorobo 2012). In order to prevent such disasters and protect the environment, it is necessary to carry 
out monitoring modelling and creation of a data base for the control and management of flood events and other natural disasters associated with climate change.

\subsection{Climate Change}

Climate change as defined by IPCC 2001 refers to any change overtime whether due to natural variability or as a result of human activities. Climate change brings about changes and variations in all aspects of hydrological circle. At some places it will result in heavy flooding while in other places it will result in drought (Ehiorobo et al, 2013).

In order to stimulate or evaluate the effect of climate change on natural resources, the spatial and temporal variability of the water balance must be characterised under new climate conditions (Mark et al, 1993).

To analyse the impact of climate change on regional water balance, it requires formulation of models that can account for spatial variation in critical water balance parameters such as precipitation, soil moisture and evapotranspiration (Ehiorobo et al, 2012). In spite of extensive research on the specific impacts of climate change, research and information on the impacts of climate change on watershed systems remain scarce (Marshall and Randhir 2007, Combalicer 2010, Ehiorobo et al 2013).

Although many studies on the potential impact of climate on river flows have been published (Bates et al, 2008, Combalicer et al 2010) most of the publications are from Europe, North America, Australia, Asia and least from Africa. This is probably due to lack of adequate data particularly in a country such as Nigeria where the leaders think that acquiring data to model and fight the potential impacts of climate change is a waste of resources.

In Africa, we are only starting to understand the damaging impact of climate change. Climate change is likely to result in increase in frequency or intensity of extreme weather events. Access to observation data is a prerequisite to improving our understanding of extreme weather events. A variety of climate and non-climate processes influences flood processes resulting in river flooding, flash flood, urban floods, coastal floods etc. (Ehiorobo et al, 2013, Izinyon and Ehiorobo, 2014a and 2014b)

One of the biggest challenges in flood management and flood risk assessment is the lack of availability of data. For many extreme events such as precipitation there is currently insufficient information to assess recent trends and the confidence in models and understanding is inadequate to make firm projections of weather events.

Flood magnitude depends on precipitation intensity, volume, timing and phase. To take the risk of flooding properly into account requires insight into the nature and magnitude of the risk i.e. the processes that produce floods, probability of floods and their consequences including economic damage, number of casualties and how people will react to catastrophic flooding (Ehiorobo and Uso 2014, Izinyon and Ehiorobo 2015).

\subsection{Social Economic Consequences of Climate Change Induced Flooding}

Frequent flooding resulting in loss of livelihood, production and prolonged economic impact and types can trigger mass migration or population displacement. Such migrants swell the rank of urban poor living on marginal lands in cities that are prone to flood or other risks. In several cases, able bodied men are forced to migrate and the safety of women, children, the elderly and disabled who are left behind becomes an issue. This contributes to a huge economic loss for the economy as able bodied men who would have been contributing to agricultural production migrate to urban areas to increase the urban poor and in many cases are led to crime as a means of livelihood.

Flood frequency in agricultural lands result in inadequate productivity and lack of surplus income, thereby preventing investments in better agricultural practices. In coastal areas, climate change and sea level rise have the potential to significantly increase coastal erosion and flood risk. Failure to provide appropriate maintenance for infrastructures such as highways, secondary roads, bridges etc. can contribute to flood vulnerability. 


\subsection{Methods for Sustainable Environmental Monitoring and Database Development}

\subsection{Flood Frequency Analysis Using L-Moment Approach}

Many studies on flood frequency analysis are based on at site measurements. The problem with at site measurements include violation of the assumption of independence between the event values and the fact that the quantile function depends on the method of fit and its arbitrary rules, and the lack of power interest in goodness of fit tests. Another problem particularly of site with short records as obtained with most gauge stations in Nigeria is that some of the sample statistics are bounded by infection of sample size (Dalen 1987, Eslamian and Feizi 2006).

The purpose of regional analysis using L-moment is to improve the results and prediction of frequency analysis by improving the goodness of fit tests and the estimates of the distribution parameters used in single site analysis.

The steps involved in regional frequency analysis using L-moment include (Hosking, 1990; Hosking and Wallis, 1991);

a) Screening of Data: L-moment are used to construct a discordancy measure which identifies unusual sites with sample L-moment ratios markedly different from the other sites.

b) Identification of homogeneous region: the purpose of this is to form groups of stations that satisfy the homogeneity conditions. L-moment is used to construct a summary statistics in testing heterogeneity of a region.

c) Choice of a frequency distribution: L-moment ratio diagram and regional average L-moment statistics ( $\mathrm{z}$ - statistics) can be used in testing weather a candidate distribution gives a good fit to the region's data.

d) Estimation of the frequency distribution regional L-moments are used to estimate parameters of the chosen distribution. This procedure involves the fitting of the chosen distribution using the L-moments. Its parameters are estimated by equating the population L-moments derived from the observed data.

The methodology has been applied successfully in modelling regional floods in a number of case studies (Izinyon and Ehiorobo 2014a, 2014b, Izinyon and Ehiorobo 2015).

Site characteristics typically include geographical location of the site, its elevation and other physical properties associated with the site. Site characteristics may also include such parameters as the time of the year at which the annual maximum flood or extreme precipitation most frequently occur. In many cases, region may be chosen from a set of contiguous sites, based on administrative boundaries.

Once a set of physically possible regions has been defined, the next step is to test whether the proposed region is homogenous or not. The hypothesis of homogeneity is that the at site frequency distribution are the same except for a scale for a site-specific scale factor. A test of this hypothesis is based on whether the data at the $\mathrm{N}$ sites in the region are consistent with this relation between the at site frequency distribution.

Most of the tests involve a quantity $\theta$ that measures some aspect of the frequency distribution and its content in a homogenous region. The value $\theta$ may be taken as 10 - year event scaled by the mean, the coefficient of variation, a combination of L-CV and L-skewness or a combination of L-CV, L-skewness and L-Kurtosis (Hosking and Wallis, 1991).

\subsection{Monitoring and Forecasting}

Meteorologists and hydrologists can contribute to flood reduction at a specific point on a stream by issuing

i. Daily weather forecasts

ii. Advanced warning about potentially damaging conditions

iii. River stage forecast

iv. Flood forecasts (flow rate, time of occurrence, duration of peak flow, etc.) 
A unified system needs to be developed which will consist of the procedures for forecasting, warning, communication, mobilization and evacuation. The elements of the programme should consist of:

i. Flood monitoring system made up of equipment, people and procedure for rainfall and run off data acquisition, performing flood analysis and making prediction.

ii. Risk mapping, prediction flows in areas that will be flooded and issuing warning to communities and institutions

iii. Public information policy to create awareness of flood problems and inform the public promptly

iv. Emergency plan of action during and immediately after flood

Geographical information systems (GIS) can be used for flood forecasting on regional basis as follows (Ehiorobo, 2012, Al-Sabham et al 2003). The input data include basin topography, soil type, stream gauge records of each location, sizes of existing dams and the water impoundment capacity of reservoirs and records of past rainfall durations and intensities.

Given the above data sets together with a model to estimate runoff, GIS software can perform a variety of analysis including

a) magnitude of flood and the associated damage created by rainfall of high intensity over a long duration

b) if population data are available, along with population attribute data, GIS can identify any resident at risk or endangered by a particular flood event

c) If evacuation becomes necessary, GIS can be used to identify the best and safest escape routes.

\subsection{Analysis of Precipitation through the L-Moment Approach}

The L-Moment methodology used in this study is based on the National Oceanic and Atmospheric Administration (NOAA) dataset and the software used was the REFRAN-CV created by the Institute of Environment and Sustainability of the European Commission Joint Research Centre at Ispra, Italy. Preliminary studies carried out involved collection of precipitation data from station 1-D and station 3D coordinates $(\phi, \lambda, H)$. Annual mean precipitation data as well as monthly values. The values were expressed in millimetres of rainfall as measured in time t. Once precipitation data have been obtained; the data were checked for errors and formatted. Simple shape files were created for station datasets and precipitation data linked to them. Mosaics were created for bioclimatic variables as well as for altitudes. Masked layers were then created using administrative boundaries downloaded from DIVA-GIS online data base. The L- moment methodology used in the study in REFRAN-CV is shown in the flow chart (Figure 1).

\begin{tabular}{|c|c|}
\hline 1) & Data collection and preparation \\
\hline \multicolumn{2}{|r|}{$\downarrow$} \\
\hline 2) & Identification of homogenous regions \\
\hline \multicolumn{2}{|r|}{$\downarrow$} \\
\hline 3) & Identification of Probability Distribution \\
\hline \multicolumn{2}{|r|}{$\downarrow$} \\
\hline 4) & Interpolation \\
\hline \multicolumn{2}{|r|}{$\downarrow$} \\
\hline 5) & L-Moment Maps \\
\hline 6) & Final Maps; Return Period and Probability \\
\hline
\end{tabular}

Figure 1: Flow chart of activities for L- Moment modelling 
The software used (REFRAN-CV) enabled us to produce maps showing estimation for the return period $5,10,50$ and 100 years. The L-moment maps generated for 5 and 50 years in respect of Western Africa region and Nigeria are presented in Figure 2 - Figure 4.

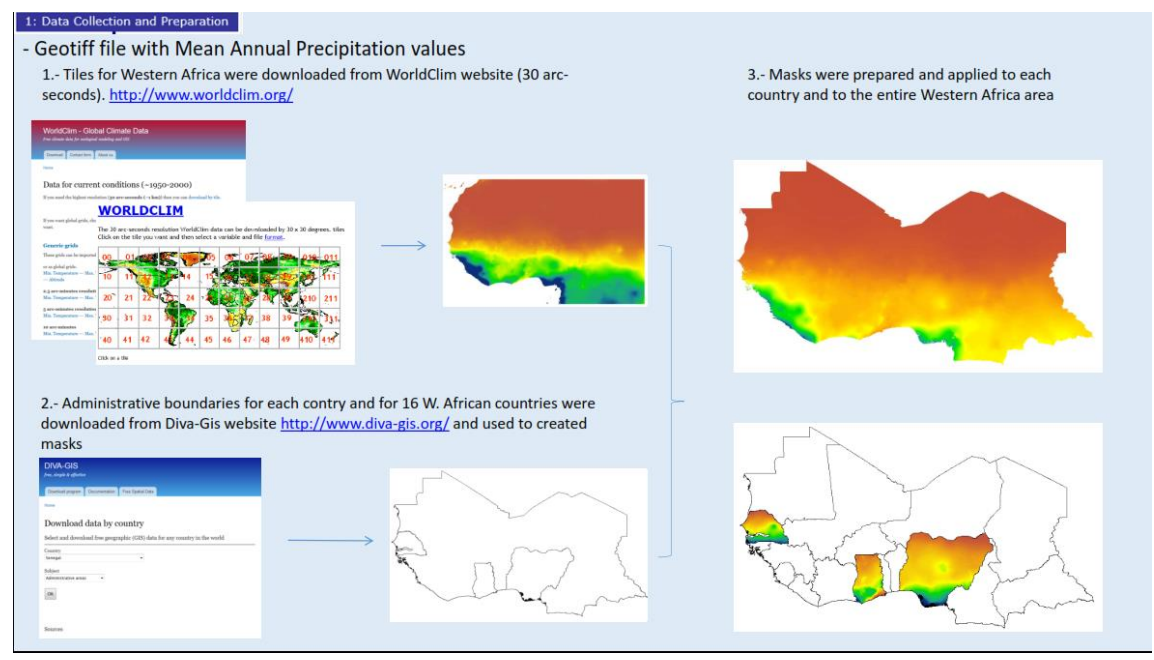

Figure 2: Mean Annual Precipitation Values for Africa and Western African CoE Countries (Source: EU-NEPAD Western African COE 2016)

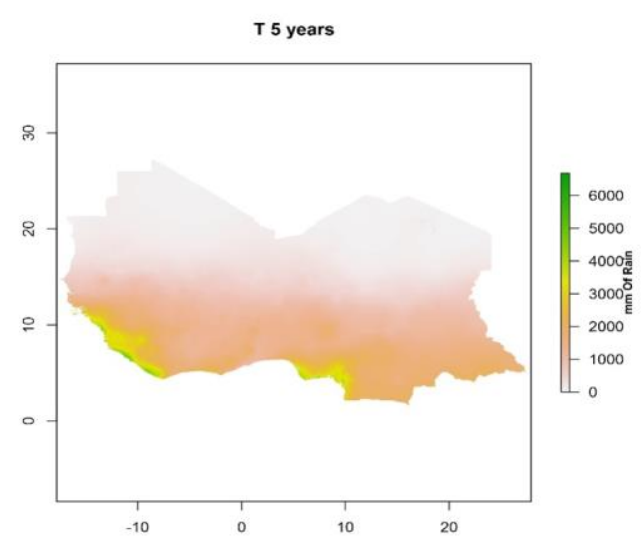

(a)

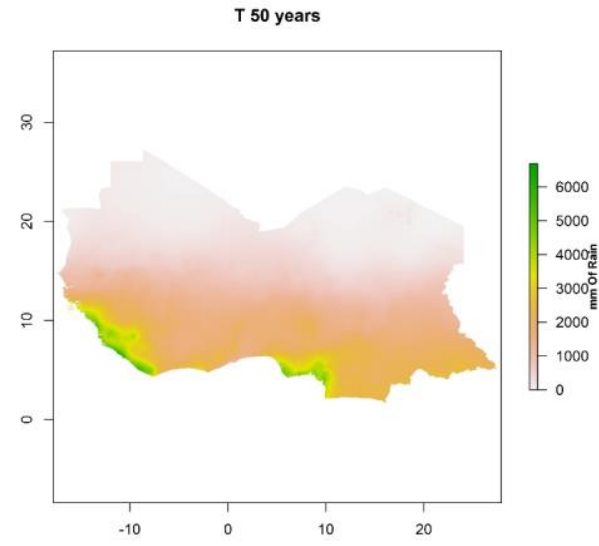

(b)

Figure 3: Precipitation Map of Western Africa for (a) 5 years and (b) 50 years Return Period

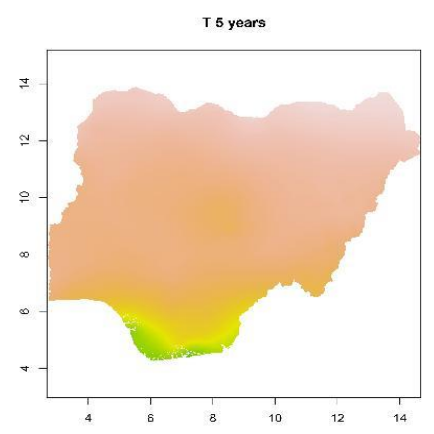

(a)

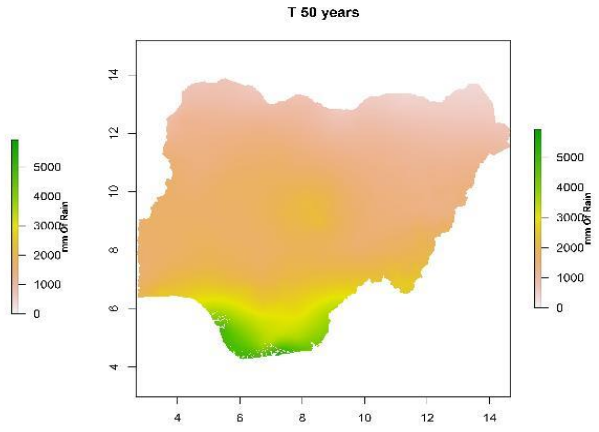

(b)

Figure 4: Precipitation Map of Nigeria for (a) 5 years and (b) 50 years Return Period

In order to evaluate the quality of the results, the following parameters are used

a) Heterogeneity - Mean $\mathrm{H}_{\mathrm{i}}$

$\mathrm{H}_{\mathrm{i}}$ measures the variability of coefficient of variations 
$\mathrm{Lcv}=\mathrm{H}_{\mathrm{i}} \geq 3=$ Heterogeneous

b) Discordancy

$\mathrm{D}_{\mathrm{i}}=$ measures the degree of difference between the station L-Moment and the regional LMoments. Critical values depend on the number of stations per region

c) Goodness of Fit

$Z^{\text {Dist }}=$ measures how well the L-skewness and L- Kurtosis of the fitted distribution match the regional average $\mathrm{L}$ - skew and $\mathrm{L}-\mathrm{Kurt}$ of the observed data

$\mathrm{Z}^{\text {Dist }}<|1.64|$

\subsection{Discussion of Results}

In this type of study, the aim of regionalization is to form groups of sites that approximately satisfy homogeneity condition that the site frequency distributions are identical apart from a site specific scale factor.

A major challenge associated with precipitation frequency analysis include:

a) Low density of meteorological stations which is peculiar to Nigeria among the collaborating West African countries.

b) Inadequate length of historical time series

c) Measurement errors

d) Constraints associated with the different methods.

Despite these problems, the precipitation frequency analysis can help in defining public or government policies with respect to:
a) Water resource management
b) Identification of the most appropriate crop variety to plant where and when
c) Prevention of food security crisis
d) Hazard mitigation and management
e) Engineering design of appropriate infrastructure for national socio-economic development.

\subsection{Conclusion and Recommendations}

Access to available observation data is a prerequisite to improving our understanding of climate change induced weather events. As the risk of flooding and other climate change induced disaster continue to increase, it will be necessary to adopt appropriate technologies for the monitoring and forecasting of these events leading to disasters.

Flood risk management plans in Nigeria should be regarded as a fundamental element of development planning. It should be designed into infrastructure projects at an early stage taking into account the social and economic development opportunities increased flood protection can bring to the country. As reported by IPCC, due to global warming, many sub-systems of the global water cycle are likely to intensify resulting in many regions experiencing increase in flood magnitude and flood frequency. Climate change is making weather less predictable, rains more uncertain and heavy storm rainfall more likely. Sea level rise increases the risk of coastal flooding. By 2080's, more people all over the world will be flooded due to sea level rise.

It is recommended that the federal government adopt the European model for flood management at the national level. In this system countries sharing boarder with the River Niger to the west and those sharing boarder with Benue River to the east should share joint river basin commission to manage both the Niger and the Benue Rivers. The purpose is to have an integrated river basin management whereby data are shared, legislature streamlined for the management of the rivers. 
At the state level, states boarding the lower Niger River such as Kogi, Edo, Delta, Anambra Rivers and Bayelsa should set up a joint commission for the management of the River Niger. This commission will also be responsible for gathering of hydrometric data and management of the basin. This commission should also be responsible for setting up flood risk programs and projects that will allow the states to have acceptable levels of protection from floods

The existing river basin development authorities in Nigeria should concentrate more on hydrometric and meteorological date acquisition for various areas within their domain in the country rather than competing for contract award with ministries, Universities and other higher institutions should be well equipped for river flow monitoring, research and development in watershed management etc.

In order to combat the devastating effect of flooding and its impact on the social economic development of the country, there is the urgent need for the National Space Research And Development Agency NASRDA, Centre For Atmospheric Research and some selected universities to carry out collaborative research in the area of monitoring, forecasting and management of various form of hazards associated with climate change.

\section{References}

Al-Sabham W, Milligan M and Blackburn G.A. (2003)"' A Real-time Hydrological model for flood prediction using GIS and the WWW". Journal of Computers Environment and Urban systems, Elsevier series, 27 (2003) pp. 9-32

Bates B.C, Kundzewicz Z.W., Wu S. and Palutikof J.P. (2008),"'Climate Change and Water'”. Technical Paper on Intergovernmental Panel On Climate Change IPCC Secretariat General

Combalicer E.A, Cruz R.V.O, Lee S.H And IM S( 2010),"Assessing Climate Change Impacts On Water Balance In The Mount Makiling Forest Philippines"' Journal Of Earth System Science 119(3) Pp. 265-283

Dalen J (1987) “Algebraic Bounds on Standardized Simple Moments" Statistics and Probability letters 5 pp $329-333$.

Earth Observation (2016) "Natural Hazards Global Maps". Accessed at http://earthobservation.nasa.gov/features/GlobalWarming on 11th April 2016

Ehiorobo J. O. (2013) “Analysis of Precipitation through L-Moment Approach" A paper presented at the final workshop of the EU-NEPAD Africa Water Centre of Excellence Support Project, 30 Sept 2nd Oct. 2013, Dakar.

Ehiorobo J. O. and Uso N. (2014), "Flood Frequency Analysis in the River Niger Basin at Onitsha Bridge Head". Journal of Engineering Research, UNILAG, Vol 19(1) pp. 33-34

Ehiorobo J. O., Izinyon O. C. and Ilaboya I. R. (2013), "Effect of Climate Change on the River Flow regimes in the Mangrove and tropical rainforest of the Niger Delta region of Nigeria". Research Journal in Engineering and Applied Science RJEAS. Academy Resource, Seattle, USA. Vol 2(4) pp.256-261)

Ehiorobo J.O and Izinyon O.C. (2011), "Measurements and Documentation for flood and erosion monitoring and control in the Niger Delta states of Nigeria". http://www.fig.net/pub/fig2011/papers/ts07

Ehiorobo J.O. (2012), "Sustainable Flood Risk Assessment and Flood Management in Nigeria: Obstacles, Challenges and Solutions". http://www.nice-nigeria.org/publication

Ehiorobo J.O., Izinyon O.C. and Ilaboya I. R. (2012), "Effects of Climate Change in the River Flow regimes in the Mangrove and Tropical Rain forest region of West Africa" Proceedings of the conference on Exchange of Experience in Water Resource Management between Africa, China, Latin America and Europe" Edited by Georgia Donning, Murray Biender, Andrea Leone and Cesar Carmina Moreno, European Commission Joint Research Centre (JRC). Institute of the Environmental and sustainability Ispra, Italy. Published by Publication House, European Union, Luxembourg pp. 113-117 
Eslamian S. and Feizi H (2006) "Maximum Monthly Rainfall Analysis using L-Moments for an Arid Region in Isfahan Province, Iran" Journal of Applied Meteorology and Climatology, Vol. 46(4) pp 494 -503 .

Hoskings J. R. M (1990) "L-Moment Analysis and Estimation of Distributions using Linear Combinations of Order Statistics" Journal of the Royal Statistical Society, Vol. 52(1) pp 105 - 124.

Hoskings J. R. M and Wallis J. R (1991) "Regional Frequency Analysis using L-Moments" Research Rep-Watson Research Centre, IBM Research Division, York Town Heights, NY.

Izinyon O.C. and Ehiorobo J. O. (2014a), "L-Moment method for flood frequency analysis for River Owan in Benin- Owena River Basin, Nigeria". Current Advances in Civil Engineering Vol 3 (1) pp. 110

Izinyon O.C. and Ehiorobo J. O. (2014b), "L-Moment Approach for Flood Frequency Analysis of River Okhuwan in Benin-Owena River Basin in Nigeria". Nigerian Journal of Technology (NIJOTECH) Vol 33 (1) pp. 10-18

Izinyon O.C. and Ehiorobo J. O. (2015), "Modelling of Extreme Rainfall of selected Nigerian cities using Generalized Extreme Value (GEV) Distribution and L- Moment procedure". Proceedings of the National Union of Radio and Planetary science (NUPRS) conference, Enugu 2015

Mark D, King G.A. and Dolph J (1993), "Implications of the Climate Change for the Water Balance of the Colombia River Basin, USA". Climate Research Vol. 2 pp. 203-213

Marshall E. and Randhir T. (2007), "Effects of Climate Change on watershed systems: A Regional Analysis". Climate Change. DOI: 10.1007/S10584-007-9389-2 